\title{
Analysis of sea condition of Jiaolong deep-sea manned submersible operating in the South China Sea
}

\author{
Liu Xiaohui ${ }^{1}$, Qin Shengjie ${ }^{1}$, Yang Lei ${ }^{1}$, Qi Haibin ${ }^{1}$ and Zhang Qi ${ }^{2}$ \\ ${ }^{1}$ National Deep Sea Center, Qingdao, Shandong, China \\ ${ }^{2}$ Qingdao Agricultural University, Qingdao, Shandong, China
}

\begin{abstract}
The South China Sea is the sea area with the largest area, the largest depth, the most abundant oil and gas resources and the most comprehensive biological species in China. The further exploration of the South China Sea with manned submersible and other major deep-sea equipment is of great significance to China's deep-sea scientific investigation. In this paper, Jiaolong manned submersible was taken as an example. In order to explore the operation window to guarantee the operation safety of manned submersible and improve the efficiency of voyage scientific investigation, this paper combined the global wave return data and the wave data based on satellite remote sensing to focus on the Marine environment characteristics in the South China Sea. According to the operational design parameters of Jiaolong, in the South China Sea, the most appropriate operating time window is from April to September, and the rest of the time, proper sea conditions should be selected for the operation.
\end{abstract}

\section{Introduction}

Located in the southern part of the Chinese mainland, the South China Sea is the western part of the Pacific Ocean and one of the three major marginal seas of China. The natural sea area of the South China Sea covers an area of about 3.5 million square kilometres, among which China's territorial sea covers an area of about 2.1 million square kilometres. It is the largest and deepest sea area in China's offshore waters, with an average depth of 1,212 meters and a maximum depth of 5,559 meters. The South China Sea is rich in Marine oil, gas and mineral resources, as well as tropical and subtropical biological resources. It is the most important island and tropical ecosystem distribution area in China ${ }^{[1]}$. For a long time, China has carried out many scientific expeditions in the South China Sea. With the rapid development of deepsea exploration equipment in recent years, the frequency of scientific expeditions to the South China Sea has gradually increased, among which the most representative one is Jiaolong, China's first deep-sea manned submersible independently developed and integrated. Jiaolong can carry out layout and recovery operations under level-four sea conditions and level-five sea conditions ${ }^{[2]}$. According to the author's many dives in the South China Sea as a pilot of Jiaolong, the impact of sea waves and currents on the safety of submersible is the biggest one in the stages of layout, recovery and floating ${ }^{[3]}$. According to the operation characteristics of Jiaolong manned submersible and the basic requirements of operation sea conditions, combined with the global wave return data and the wave data based on satellite remote sensing, this paper focuses on the Marine environment characteristics of the South China Sea, so as to provide reference for the selection of the time window for the follow-up operation of Jiaolong.

\section{Data and analysis methods}

In this paper, the characteristics of wind field, wave field, tropical cyclone and surface flow field in the South China Sea are analyzed by using the synoptic analysis method, combined with the corrected data of wind wave, cyclone and ocean current, and the main weather systems in the South China Sea are briefly analyzed for the characteristics and reasons.

At present, wind and wave analysis studies in the South China Sea are mostly based on HY-2 satellite altimeter data ${ }^{[4]}$, focusing on the annual mean wind field and wave field in the South China Sea, and focusing on the establishment of the wind and wave relationship model in the South China Sea.Based on ERA-Interim high resolution reanalysis data, this paper analyzes the wind and wave fields in the South China Sea for a long time series and establishes a wind and wave relationship model suitable for the South China Sea.The data obtained by four dimensional variational assimilation technique and deviation correction of satellite data have high accuracy.For the data of tropical cyclones and ocean currents in the South China Sea, the authoritative data provided by JTWC (Joint Typhoon Warning Center) and OFES (Global Ocean Circulation Model) are adopted.

\footnotetext{
* Corresponding author: 1xh@ndsc.org.cn
} 


\section{Data comparison results and conclusions}

\subsection{Analysis of monthly mean sea waves in the South China Sea over the years}

The size of the sea wave is very important to the operation safety of the submersible in the stage of laying and recovery.During the laying stage of the submersible, the A-frame hoisting submersible is put out to the outboard. During the lowering process of the main cable, the size and direction of the waves will significantly affect the entry posture of the submersible and the safety of the frogman when unwinding the main cable.During the recovery phase of the submersible, the tension of the towing cable also depends on immediate wave conditions.Therefore, it is necessary to pay attention to the influence of sea waves on the safety of submersible operation.

Due to the influence of wind factors, the effective wave height and mean wave period in the South China Sea have obvious monthly changes.According to the comparative analysis in Figure 1, it can be seen that the maximum effective wave height in the South China Sea is from November to February of the next year, in which the maximum effective wave height occurs in December and can reach 3.0-3.5 meters. The minimum effective wave height is about $1.0-1.5 \mathrm{~m}$ from April to July and September, which is relatively more suitable for manned submersible operations.
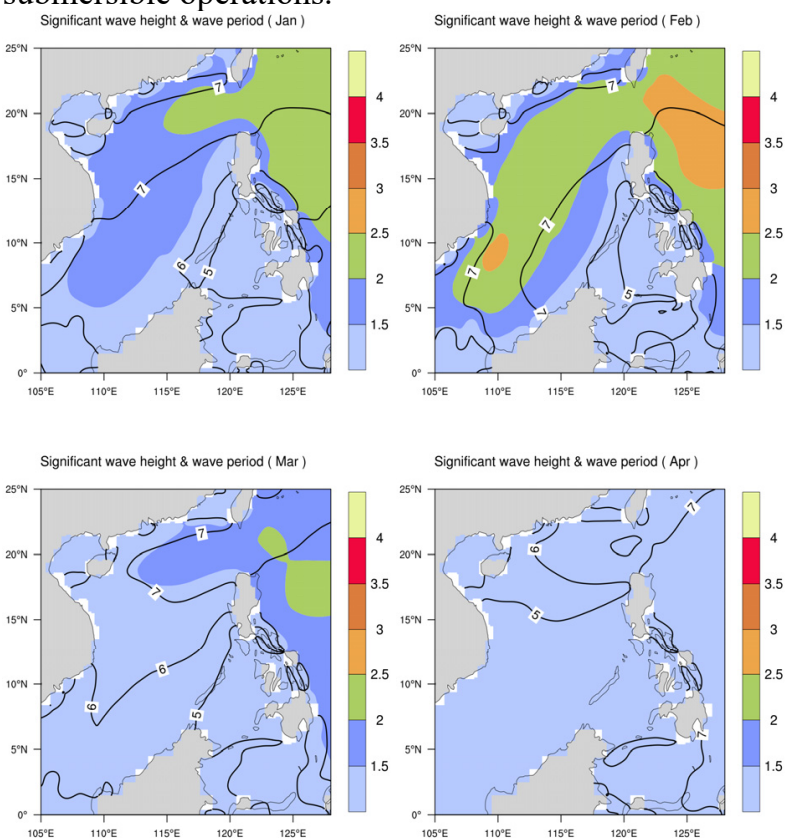
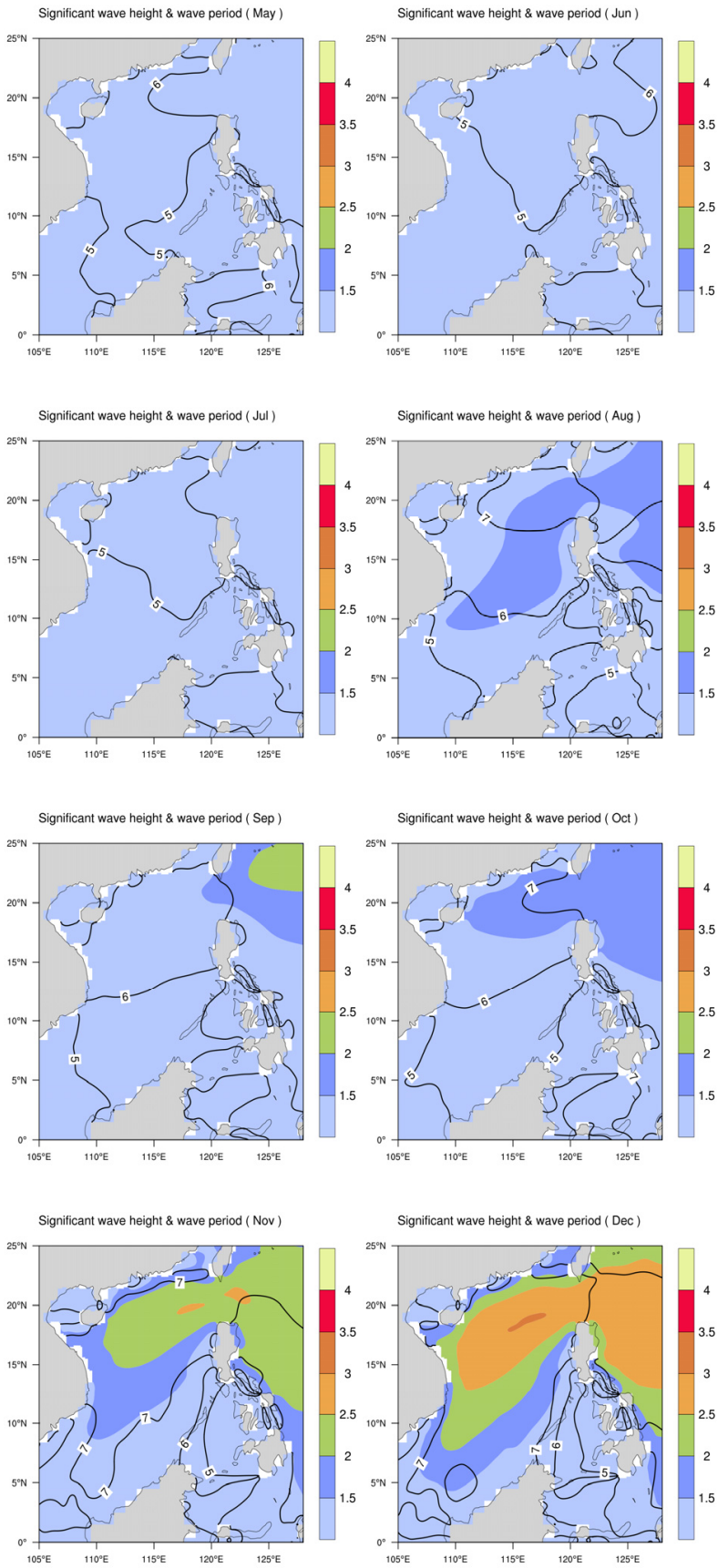

Fig. 1 Map of effective wave height and wave period in South China Sea (January to December)

\subsection{Study on the regularity of surface flow field in the South China Sea}

The selection of manned submersible diving operation points depends on the conventional survey means of the mother ship, such as CTD, multi-beam, auxiliary ROV, etc.After the dive point is determined, the manned submersible is usually placed near the dive point and dives to the predetermined dive point independently by its own gravity to carry out operations.During the period from when the submersible is laid on the water surface to the beginning of diving, the influence of the flow field on the surface of sea water on the submersible is directly related to whether the submersible can dive to the 
predetermined dive point.Therefore, we need to pay more attention to the surface flow field in the sea area where the submersible operates and explore its change rules.

By comparative analysis, the circulation in the South China Sea was cyclonic circulation from November to March of the following year, and the west branch of the circulation, namely the south-southwest Vietnam coastal current, had the highest velocity in December.The overall basin-scale velocity in May is the lowest of the year, making it the best month for manned submersible operations.
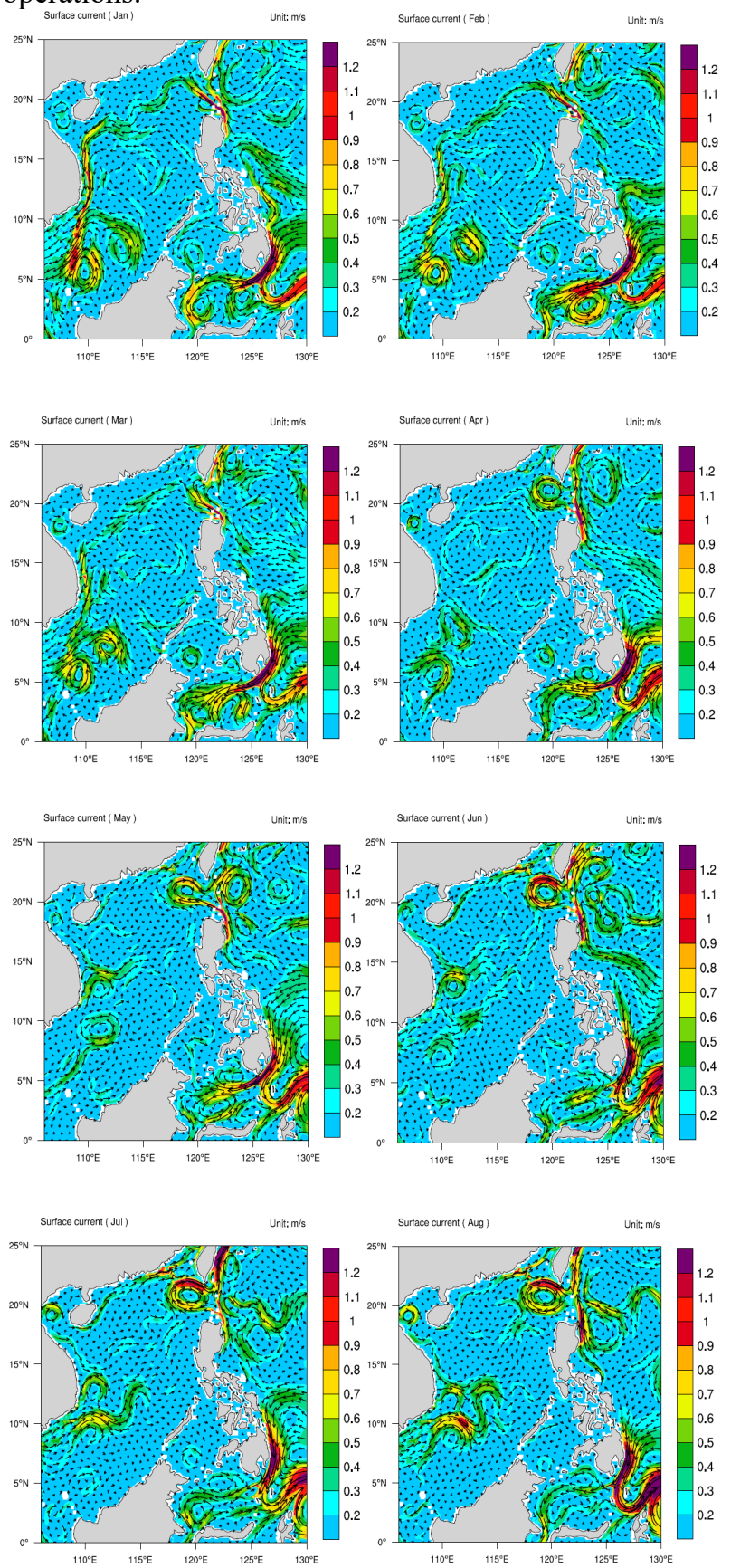
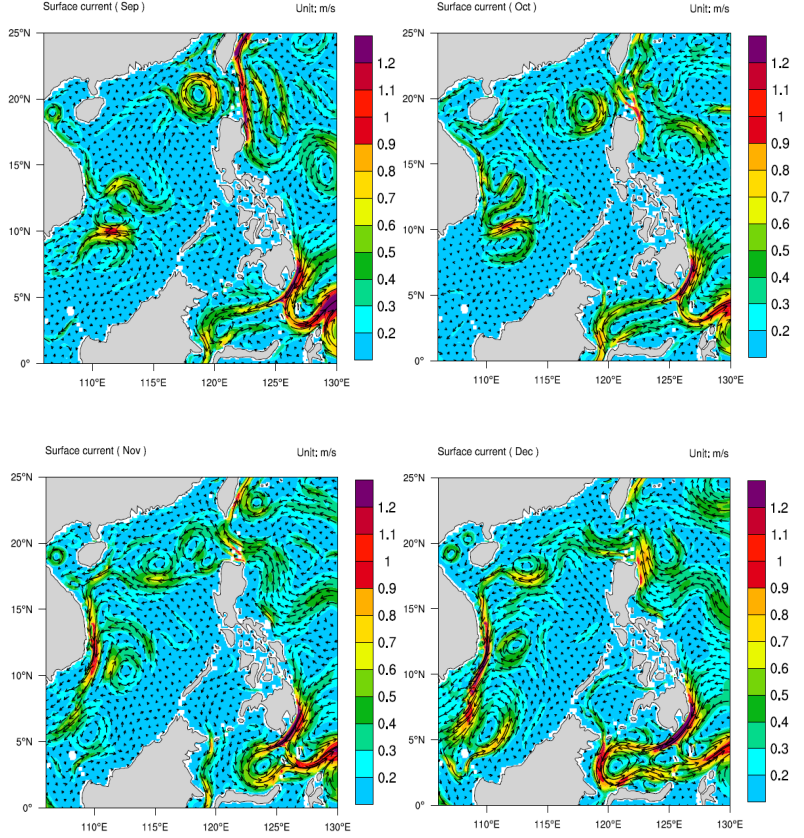

Fig.2 Surface flow field map of the South China Sea

\section{Safety analysis of sea operation of Jiaolong}

Jiaolong is required to deploy and recover at sea level 4 and below, and recover at sea level 5 and below ${ }^{[5]}$.According to the operation requirements, this paper makes statistics of the level 4 and level 5 sea conditions in the South China Sea.As shown in Figure 3 and Figure 4.

May and June are the months with the best average state of sea in a year, and the number of days exceeding class 4 sea state in the whole South China Sea is less than 3 in each month.The sea conditions in April and July to September are also good, with about 3-6 days of Level 4 sea conditions, but the number of days over Level 5 sea conditions is less than 3 days.In other months, the sea state level increased. December to January was the period of the worst sea state. In most areas, the number of days exceeding sea state level 4 in each month was more than 15 days, and the number of

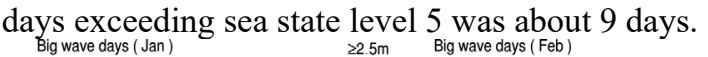

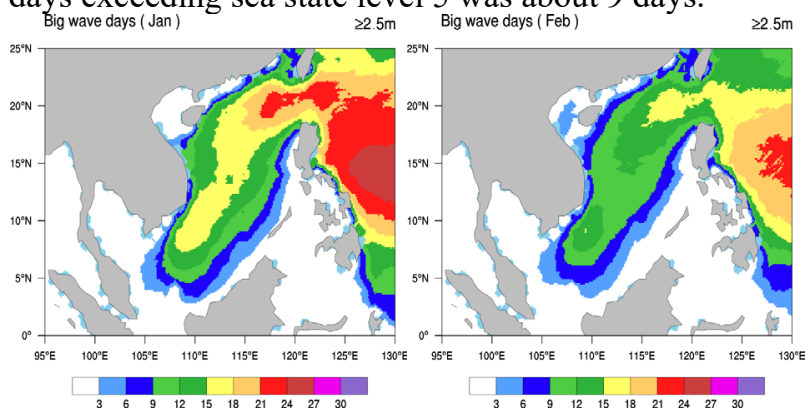



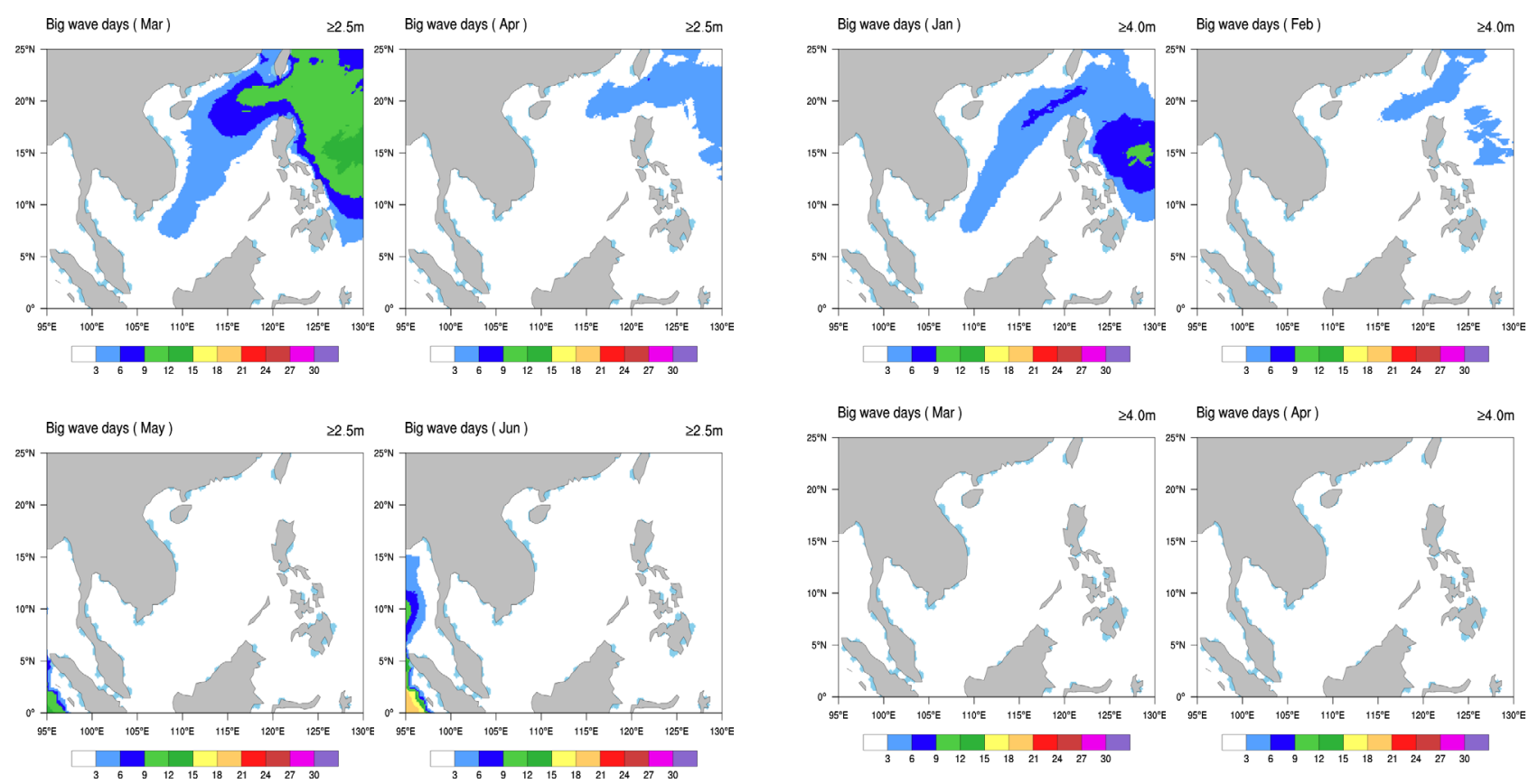
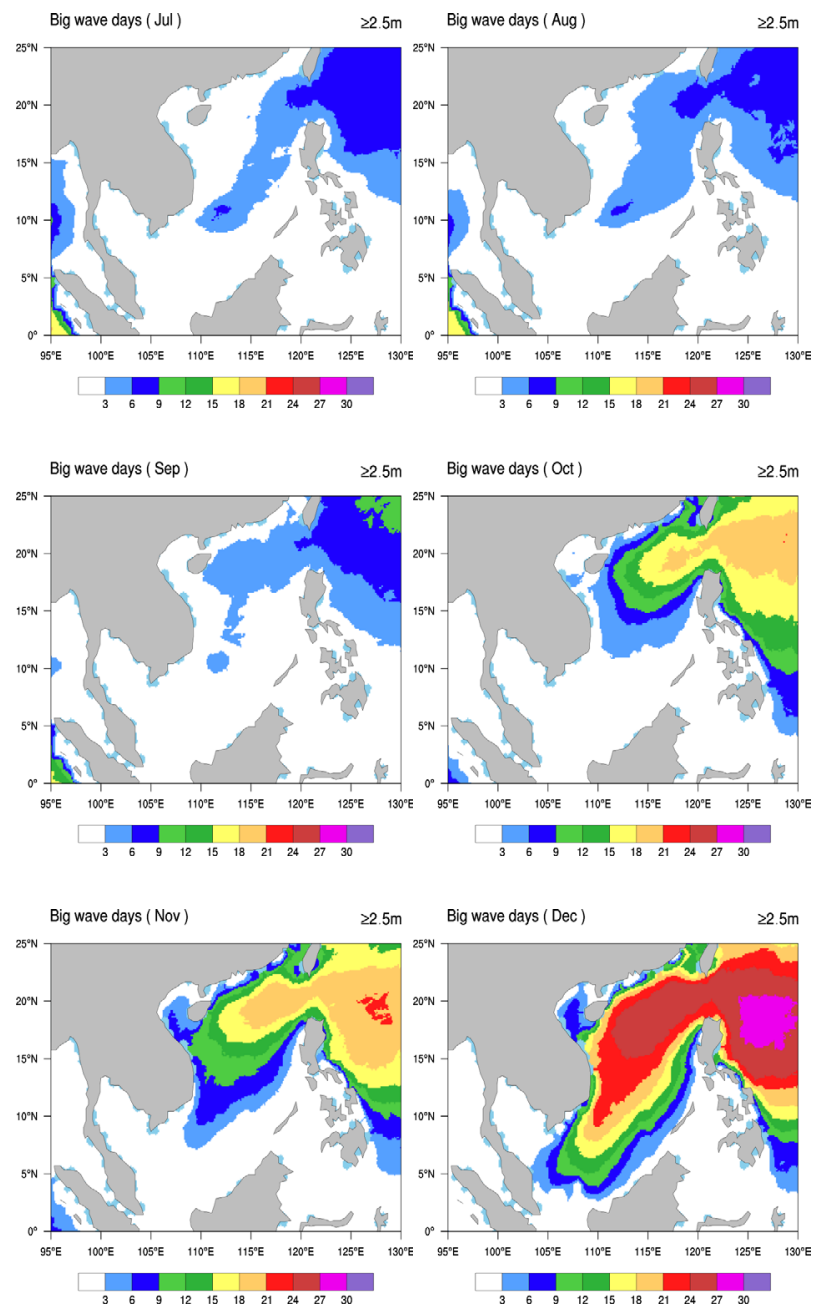

Fig. 3. Statistics of days with sea state above class 4 in February
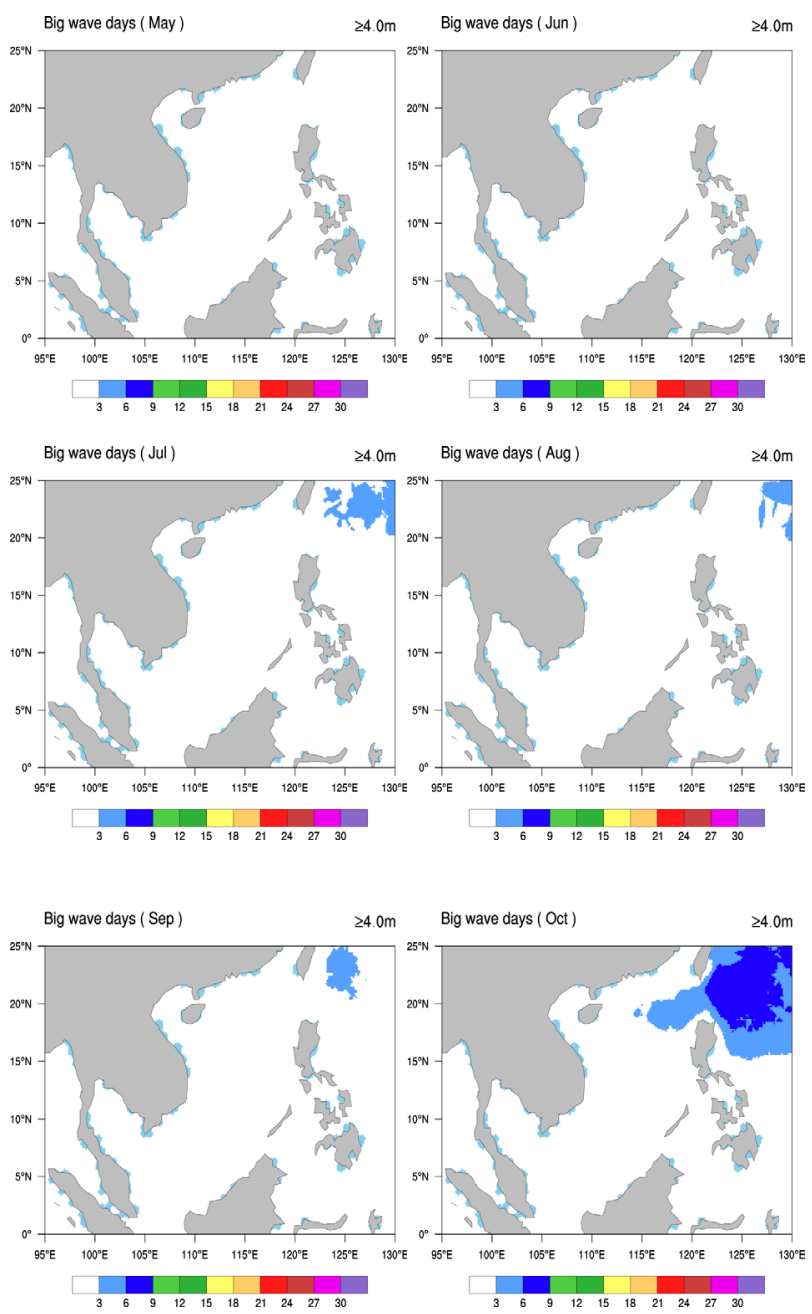


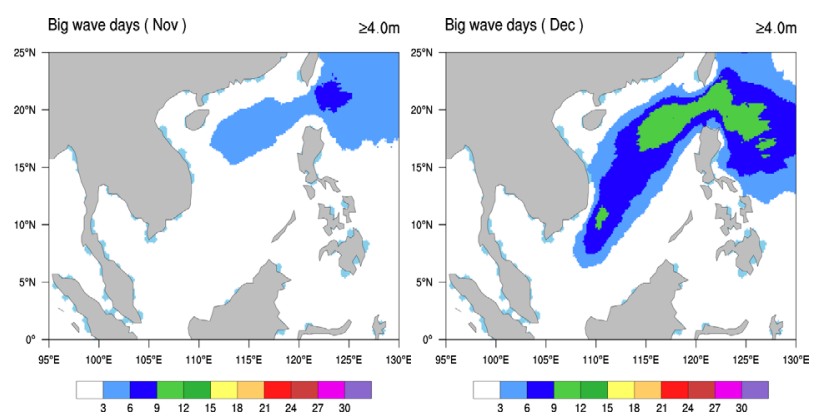

Fig. 4. Statistics of days with sea state above class 5 in February

\section{Conclusion}

(1) The monthly effective wave height and mean wave period in the South China Sea show obvious intermonthly variations.According to the comparative analysis in Figure 1, it can be seen that the maximum effective wave height in the South China Sea is from November to February of the next year, in which the maximum effective wave height occurs in December and can reach 3.0-3.5 meters. The minimum effective wave height is about $1.0-1.5 \mathrm{~m}$ from April to July and September, which is relatively more suitable for manned submersible operations.

(2) Through comparative analysis, the circulation in the South China Sea from November to March of the next year was cyclonic circulation, and the west branch of the circulation, namely the south-southwest Vietnam coastal current, had the highest velocity in December.The overall basin-scale velocity in May is the lowest of the year, making it the best month for manned submersible operations.

(3) According to the requirements of level-4 sea state placement and level-5 sea state recovery for Jiaolong manned submersible, the best operating window for Jiaolong in the South China Sea is from April to September every year.In order to ensure the operation safety of manned submersible, the operation at other times shall refer to the immediate weather and wave current conditions..

\section{References}

1. Wu S.H, Zhang H.Y, Jiao D.F, et al.(2020) Prospect of seabed mineral resources exploitation in the South China Sea. J. Science Technology and Engineering,20:12673-12682

2. Liu F, Cui W.C, Li X.Y. (2010) China' s first deepsea manned submersible-Jiaolong. J. Science China: Earth Sciences, 40: 1617-1620.

3. Qin S.J, Zhang Y, Ding Z.J et al. (2019) Statistics and analysis of structural defects of Jiaolong manned submersible. J. Ship and Ocean Engineering, 48: $140-142+147$.

4. Zhang S.Q, Hao Z.Z, Deng M.H, Gong F.(2017) Analysis of wind and wave relationship in the South
China Sea based on HY-2 satellite observation. J. Journal of Applied Oceanography, 36:327-332.

5. Ding Z.J, Liu F, Li X.Y, et al. (2017) Operation rules for the diving of manned submersible. $\mathrm{S}$. National Technical Committee on Ocean of Standardization Administration. HY/T 225-2017 